\title{
Monitoring of firmness evolution of peaches during storage by combining acoustic and impact methods
}

\author{
B. Diezma-Iglesias ，C. Valero ，F.J. García-Ramos ，M. Ruiz-Altisent \\ Rural Engineuring Department, Physical Properties Laboratory, Polytechnic Unitersity of Madrid, \\ E.T.S.I.A. Avda. Complutense stn. 28040 Madrid. Spain \\ Agriculture and Agricultural Economy Department. University of Zaragoza. Huesca. Spain
}

\begin{abstract}
Firmness is a very important quality property in peach. The storage of peach affects its subsequent softening process and shelf life. The temperature and duration of storage mainly influence the firmness of stored fruit, and monitoring the evolution of fruits enables producers to manage its commercial life. The objective of the present study was to use non-destructive acoustic and impact tests to estimate firmness of peaches and to elucidate the influenec of storage temperature and of time on the softening process of peach. Continuous and classification models based on variables obtained from non-destructive methods were developed. Parameters obtained from non-destructive methods were compared to destructive reference tests. The maximum force in ball compression correlated well with the maximum acceleration from impact test $\left(r^{2}=0.75\right)$, and with a band magnitude parameter from acoustic test $\left(r^{2}=-0.71\right)$. Combining impact and acoustic parameters, the multiple correlation coefficient increases up to 0.91 (adjusted $R^{2}=0.82$ ) in the prediction of the maximum force in ball compression. Classification models based on both non-destructive parametcrs and sorting peaches into two classes of firmness, showed scores of well classificd higher than $90 \%$.
\end{abstract}

Keywords: Non-destructive methods; Fruit quality; Firmness; Pcach; Acoustic technique; Impact technique

\section{Introduction}

Firmness is a very important quality property in peach. Determination of the storage time effect on the evolution of this quality is a desirable objective for producers, distributors and market agents, who need reliable firmness measuring instruments for commercial purpose.

Previous studies carried out by different researchers show that impact techniques can be used to evaluate firmness of fruits successfully (Chen \& Ruiz-Altisent, 1993; Delwiche, Arévalo, \& Mechlschau, 1996; Jarén,
Ruiz-Altiscnt, \& Pérez de Rucda, 1992). The force response of an elastic sphere impacting a rigid surface is governed by the impacting velocity, mass, radius of curvature, elastic modulus, and Poisson's ratio of the sphere. It had being found that the impact of a fruit on a rigid surface can be closely modelled by the impact of an elastic sphere and that the firmness of a fruit has a direct effect on the impact force response. A problem inherent to the technique of dropping the fruit on a force sensor is that the impact force is also a function of the mass and radius of curvature of the fruit. A different approach has been to impact the fruit with a small spherical impactor of known mass and radius of curvature and measure the acceleration of the impactor. The advantage of this method is that the measured impactacceleration response is independent of the fruit mass 
and is less sensitive to the variation of the radius of curvature of the fruit.

An impact device for firmness testing of fruits was developed by Chen and Ruiz-Altisent (1996). It consisted of a semi-spherical impacting tip attached to the end of a pivoting arm. Impact is done by swinging the impactor to collide laterally with the tested object. A small accelerometer is mounted behind the impacting tip. Further versions have been developed at the Physical Properties Laboratory (LPF) to obtain systems with better data resolution, signal-noise ratio and precision (Diezma et al., 2000): "LPF-Lateral Impact Sensor 2.0". This lateral impact sensor has been modified and installed in an experimental fruit packing line (GarcíaRamos et al., 2003; Homer, 2003). An on-line impactor, based on a spherical tip impacting vertically on fruit using aerodynamic impulse is commercially available (Valero, García-Ramos, De Merlo, Ruiz-Altisent, \& Howarth, 2004).

In biological tissues, vibrational behaviour of fruits has been used as an indicator of maturity and post-harvest ripeness based on the elastic properties of the tissue. Non-destructive techniques using sonic characteristics of the fruit tissue have been applied for measuring firmness and for detecting internal disorders in several products such as apples, pears, avocados and melons. Determination of the natural frequencies of fruits and vegetables as a mean of measuring firmness has been suggested by several authors (Armstrong, Stone, \& Brusewitz, 1997; De Baerdemaeker, Lemaitre, \& Meire, 1982; De Belie, Schotte, Coucke, \& De Baerdemaeker, 2000; Farabee \& Stone, 1991). According to theory, resonant frequencies of a specimen are also proportional to its dimensions, density and Poisson's ratio. Several authors have used mass to approximate the combination of density and dimensions in order to avoid these influences in the estimation of firmness by vibrational methods, different stiffness coefficients have been applied. A first stiffness coefficient was proposed from experimental results, which include resonant frequency and mass, $f^{2}(\mathrm{~m})$ (Abbott, Bachman, Childers, \& Fitzgerald, 1968). Based on the spherical resonator model other stiffness coefficient has been calculated as $f^{2}\left(\mathrm{~m}^{2 / 3}\right)$ (Cooke, 1972).

A device developed at the Katholieke Universiteit Leuven (Belgium) is being developed into an on-line sensor (De Ketelaere, Ruiz-Altisent, Correa, De Baerdemaeker, \& Barreiro, 2001). At LPF a device, composed mainly by a microphone, a signal conditioning amplifier, a data acquisition card, structural elements, and a component to produce the mechanical impact was designed and tested in order to detect internal discontinuities in watermelon (Diezma, Ruiz-Altisent, \& Orihuel, 2002; Diezma, 2003).

Firmness in peaches can be an indicator of immaturity or overmaturity. Excessive firmness indicates an immature peach with little free juice. An overmature, soft peach can be excessively juicy and prone to bruises. Previous investigations of non-destructive firmness measurement for peaches utilized impact parameters of a fruit that was bounced onto a load cell (Delwiche, MacDonald, \& Bowers, 1987). In other researches two devices based on acoustic resonance analysis were compared and used to test firmness of fresh market peaches; one device used a contacting piezo-electric disk, while the other used a non-contacting microphone. The best results were obtained using the microphone, estimating the Effe-gi firmness with adjusted $r^{2}$ higher than 0.65 (Armstrong et al., 1997). Recently, other experimental setup has been developed using a piezo-electric film transducer to detect resonance frequencies of peach (Wang, Teng, \& Yu, 2005). Visible reflectance spectrum and impact response, using an impactor free-fall type, were used to estimate destructive Magness-Taylor firmness in several cultivars of peaches with coefficients of determination higher than 0.70 (Ruiz-Altisent, Lleó, \& Riquelme, 2005). Categorical classifications of ripeness in terms of sugar content and firmness has been carried out with methods based on near-infrared transmittance spectrometry (Carlomagno, Capozzo, Attolico, \& Distante, 2005).

Several authors have reported than impact response is better in discriminating firmness in softer fruits; whereas acoustic response seems better discriminating firmness in harder fruits (De Ketelaere et al., 2001; Shmulevich, 1998). It would be useful to check if in peaches these differences in discriminating firmness remain.

The primary objective of this research was to study and compare the applicability of two non-destructive sensing devices: "LPF-Lateral Impact Sensor 2.0" and "LPF-Acoustic Device", to determine firmness in peaches stored during different time periods.

\section{Materials and methods}

\subsection{Instrumental measurements}

\subsubsection{Impact tester}

"LPF-Lateral Impact Sensor 2.0" was used. It consists of a spherical low-mass of $10 \mathrm{~g}$, which impacts the sample, with a piezoelectric accelerometer of a sensitivity of $1 \mathrm{mV} / \mathrm{m} \mathrm{s}^{-2}$ and a range of $\pm 4900 \mathrm{~m} \mathrm{~s}^{-2}$, ENDEVCO model 256-10 (manufactured by ENDEVCO, SAN JUAN CAPISTRANO, CA 92675 USA); a spring to release the impacting mass; and an electromagnet to hold the impacting mass (Fig. 1). The position of contact to the fruit was selected on the equator, and the distance to the fruit was fixed at $2 \mathrm{~cm}$.

An external conditioning circuit adapts and amplifies the signal. The external circuit also filters the electrical impactor response to eliminate noise from the 


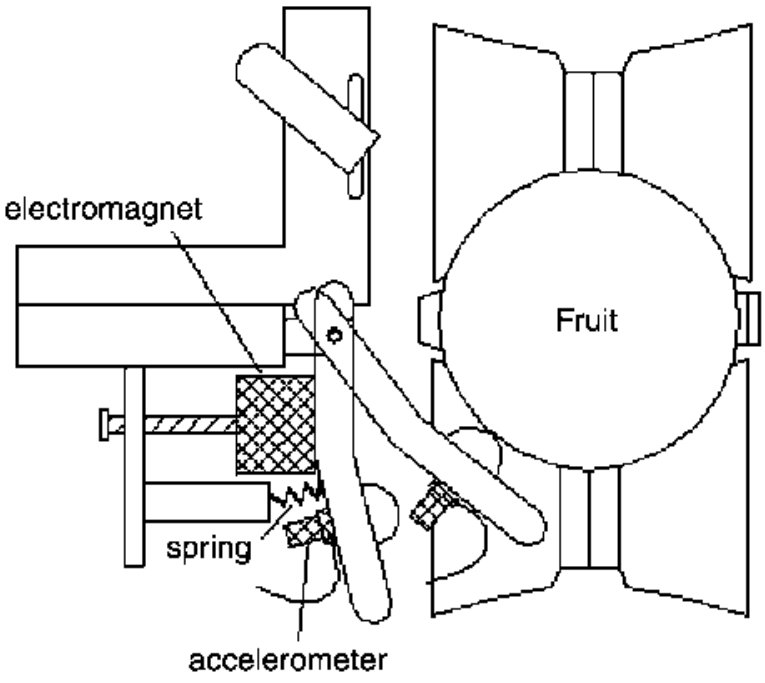

Fig. 1. Scheme of "LPF-Lateral Impact Sensor 2.0".

interesting frequency band and to prevent aliasing. An Internal Industry Standard Architecture (ISA) personal computer board connects the external system to the computer. It supports 12 bits analogy/digital converter at a tuneable sample rate up to $40 \mathrm{kHz}$. A Windowsbased software controls all the process and stores data, allowing the user an interface to manage the data and control the mcasurement process by mcans of scroll bars, check boxes, controls and sliders. Users can also configure the board and sampling parameters using a special configuration window. The software returns the user a number of parameters characterising the impact, such as acceleration versus time, velocity, deformation, energy, force versus deformation, etc. The parameter used in this work has been the maximum acceleration registered during the impact, noted ' $A_{\mathrm{LPF}}$ ' $\left(\mathrm{m} / \mathrm{s}^{2}\right)$ (Fig. 2).

\subsubsection{Acoustic tester}

Acoustic measurements were taken with a device designed at the LPF. The laboratory recording system used to acquire the acoustic impulse information is made up by a prepolarised free-field $12 \mathrm{~mm}$ microphone type 4189 Brüel and Kjaer (Naerum, Denmark), of a frequency range from $6.3 \mathrm{~Hz}$ to $20 \mathrm{kHz}$ and a sensitivity of $50 \mathrm{mV} / \mathrm{Pa}$. A signal conditioning amplifier NEXUS Brüel and Kjaer (Naerum, Denmark) supplied power and provided electrical loading to the transducer, amplified the signal and provided appropriate output drive signal and allowed selecting the optimum band-pass filters. A microphone preamplificr type $2673 \mathrm{Brücl}$ and Kjacr (Nacrum, Denmark) completed the recording system. The preamplifier amplified the signal from the microphone.

The external system was connected to a computer using a data acquisition card (CIO-DAS08, Computer Boards, Inc., Mansfield, Massachusetts, EEUU). It supported 12 bit analogue/digital converter at a tuneable sample rate up to $40 \mathrm{kHz}$, allowing the user to choose the suitable frequency to obtain the best response and avoiding aliasing for a specific application. It uses eight multiplexed analogy inputs and 24 digital in/out connoctions.

A user friendly Windows-based software, 'SanSon 1.2', was developed for the control of the process and the register of data, providing an easy output, to be used with Microsoft Excel. The software displays the acoustic signal 'time vs intensity' for each test, and saves it in an ASCII file.

A fast Fourier transform (FFT) of the signal was performed to determine the frequency spectrum, and subsequently, the natural frequencies of the watermelons. Rectangular window was used for FFT. Sampling at $40 \mathrm{kHz}$ for 4096 points results in a frequency resolution for the FFT of $9.766 \mathrm{~Hz}$. A normalized spectrum was obtained by dividing the magnitude at each frequency by the maximum magnitude of the spectrum (Farabee \& Stone, 1991). Different acoustic parameters were evaluated for spectral characterization: first resonant frequency ( $R F)$, maximum amplitude of the spectrum and band magnitude (BM) of the acoustic spectrum. The value of the band magnitude obtained by summing

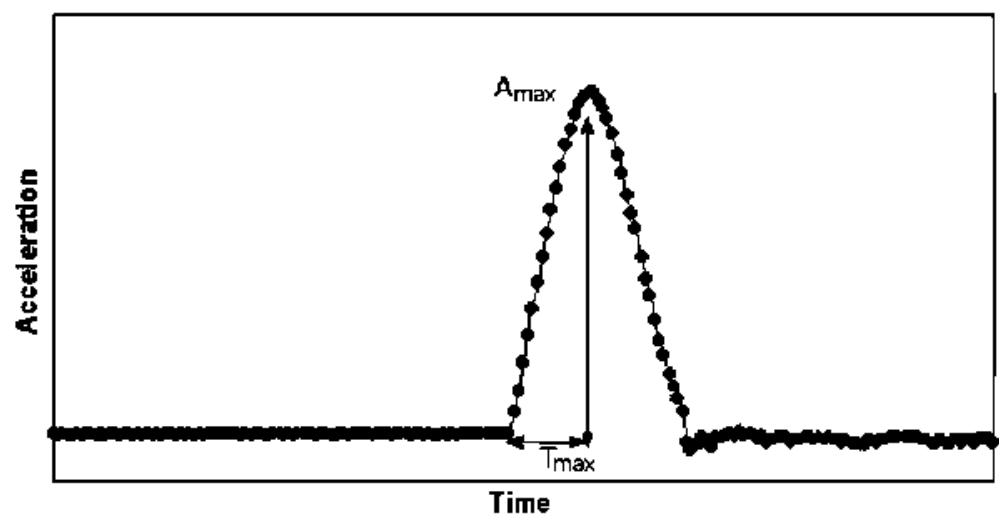

Fig. 2. Signal 'time vs. accelcration' from impact test. Parameter characterising the impact: maximum acceleration. 
Table 1

Frequency limits for band magnitude (BM) analysis

\begin{tabular}{ll}
\hline Band magnitude identifier & Frequency limits. $\mathrm{Hz}$ \\
\hline $\mathrm{BM}_{1}$ & $85-160$ \\
$\mathrm{BM}_{2}$ & $40-90$ \\
$\mathrm{BM}_{3}$ & $60-110$ \\
$\mathrm{BM}_{4}$ & $70-120$ \\
$\mathrm{BM}_{5}$ & $80-130$ \\
$\mathrm{BM}_{6}$ & $100-180$ \\
$\mathrm{BM}_{7}$ & $120-200$ \\
\hline
\end{tabular}

up the normalized spectrum magnitude between the encompassing frequencies and dividing by the sum of the spectrum magnitudes between 0 and $500 \mathrm{~Hz}$ was defined first by Farabee and Stone (1991). In our research the $\mathrm{BM}_{i(f 1-f 2)}$ were calculated by summing up the normalized spectrum magnitude between two different frequencies $(f 1$ and $f 2$ ). The bandwidths associated with the band magnitudes $\left(\mathrm{BM}_{i}\right)$ were based on the previous study by Diezma-Iglesias, Ruiz-Altisent, and Barreiro (2004) (Table 1).

The acoustic response of each fruit was measured by hitting the fruit with an impactor and detecting the output sound by a microphone on the opposite side. The impactor was made of a metal ball weighting $13 \mathrm{~g}$ fixed on a pendulum which was dropped onto the peach surface from a height of $30 \mathrm{~mm}$. A support block was formed by creating a shallow hole on the upper side of a block. A microphone, preamplifier and headphone were imbedded within the base of hollow and padding material inserted. The microphone was at a distance of 2-4 $\mathrm{mm}$ from the fruit and detected the impulse acoustic response. The headphone insulated the microphone area while the padding material provided the necessary free supporting conditions.

\subsubsection{Reference tests}

In order to determine the applicability of the impact and acoustic tester as quality sorters based on firmness detection, reference methods were performed, in order to verify and obtain conclusive correlations. Thus, simultaneously to impact and acoustic tests, two reference mechanical measurements were carried out to establish the ripeness stage of fruit. The machine used for the mechanical tests was a Texture Analyzer XT2 (Stable Micro Systems Ltd., Godalming, UK), a universal machine with a texture analyser micro processor. It is connected to a PC, and controlled by specific software. The load cell admits a maximum force of $250 \mathrm{~N}$ (resolution $0.0098 \mathrm{~N}$ and an error range of $0.025 \%$ ). Firmness tests were:

- Magness-Taylor punctures made by an $8 \mathrm{~mm}$ probe were performed on both sides of each fruit. Deformation was applied at $20 \mathrm{~mm} / \mathrm{min}$. Different parameters were calculated from of the force/deformation curve: absolute maximum force ( $\left.F_{\mathrm{MT}}{ }^{\prime}, \mathrm{N}\right)$, maximum force at the bioyield point which occurred when there was an increase in deformation with a decrease or no change of force before absolute maximum force ( ${ }^{+} F_{\text {bio, MT }}, N$ ) and slope of the curve ( ${ }^{\circ} S_{\mathrm{MT}}, \mathrm{N} / \mathrm{mm}$ ).

- Compression with ball was also carried out on whole fruit (also on both sides). Using a ball of $1.8 \mathrm{~mm}$ of diameter, a maximum deformation of $2 \mathrm{~mm}$ was applied at $20 \mathrm{~mm} / \mathrm{min}$ speed rate on the equator; deformation was immediately removed at the same speed rate. Parameters determined were: maximum force (' $F_{\mathbf{B C}}$ ', N); energy absorbed by the sample: equal to the area contained inside the load (increasing pressure) and unload (decreasing pressure) parts of the curve ( $E_{A, \mathrm{BC}}, \mathrm{N} \mathrm{mm}$ ), energy not absorbed by the sample (returned) which is the area below unloading curve (' $E_{R, \mathbf{B C}}$ ', $\mathrm{N} \mathrm{mm}$ ), elasticity degree: total deformation subtracted by permanent deformation, divided by total deformation (' $R_{\mathrm{BC}}$, \% \%).

\subsection{Materials}

A batch of 60 'Rich Lady', yellow-fleshed semifreestone peaches, was stored at $10^{\circ} \mathrm{C}$ during 10 days. Another identical batch was stored during the same period at $20^{\circ} \mathrm{C}$ (experiment A). The same experimental procedure was followed with 120 'Caterina', yellowfleshed peaches (experiment B). Both cultivars, grown under commercial conditions, were collected in Murcia (Spain). The objective was to achieve fruits in a wide range of firmness variability. The impact and the acoustic tests were carried out in the laboratory for $1,2,4,6,8$ and 10 days during the storage period, each day 10 different peaches were tested (non-destructively and destructively). In order to study the storage evolution, the impact test was also applied in all the fruits during the first day. The reference tests described were performed on each fruit. For impact, acoustic and firmness tests three measurements on opposite cheeks of each peach were performed.

Statisticaß) (version 6, StatSoft, Inc., Tulsa, Oklahoma, EEUU) software was used for data analysis. Means of three measurements on each cheek were computed and used for the rest of statistic analysis. Factor analysis and analysis of variance (ANOVA) were the methods used to select the non-destructive parameters with higher differences along the storage time and to find which of these parameters were best correlated with the reference parameters, while multilinear regression was applied to develop continuous estimation models for firmness. After discovering that the non-destructive test could have different sensitivities in different parts of the firmness range, a discontinuous estimation model was created using a piecewise linear regression with breakpoint. The breakpoint of the models is calculated 
automatically starting at the mean for the dependent variable. Clustering techniques and discriminant analysis were used to group fruits according to their values of the reference parameters and to create classification models based on non-destructive parameters.

\section{Results and discussion}

\subsection{Relationships between the variables}

In the PCA plot (Fig. 3) all the reference variables related to firmness (Magness-Taylor, compression with ball test) are grouped along an oblique factor (bottom left corner), adjacent to the impact acceleration, and orthogonal to most acoustic variables: only variable $\mathrm{BM}_{2}$ (Table 1) shows clear relationship to the reference firmness group of variables and those of the impactor, as it is positioned on the opposite extreme of the same axis. Variance explained by the first two principle components was $70.65 \%$. It can be concluded, that the main

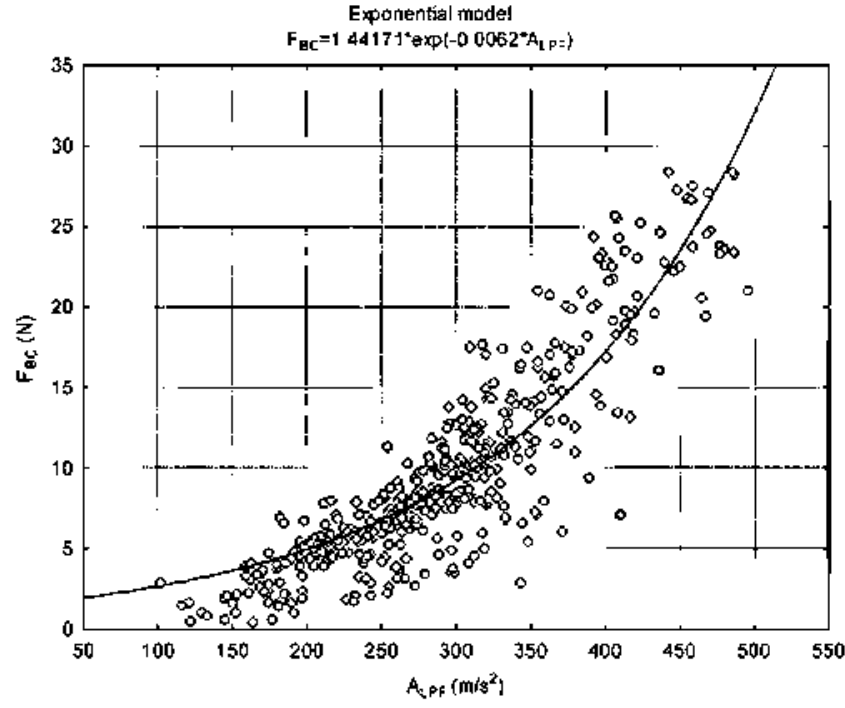

Fig. 4. Exponential model. Dependent variable: maximum force in ball compression, $F_{\mathrm{BC}}$; independent variable: maximum acceleration, $A_{\mathrm{LPF}}$ of impact test.

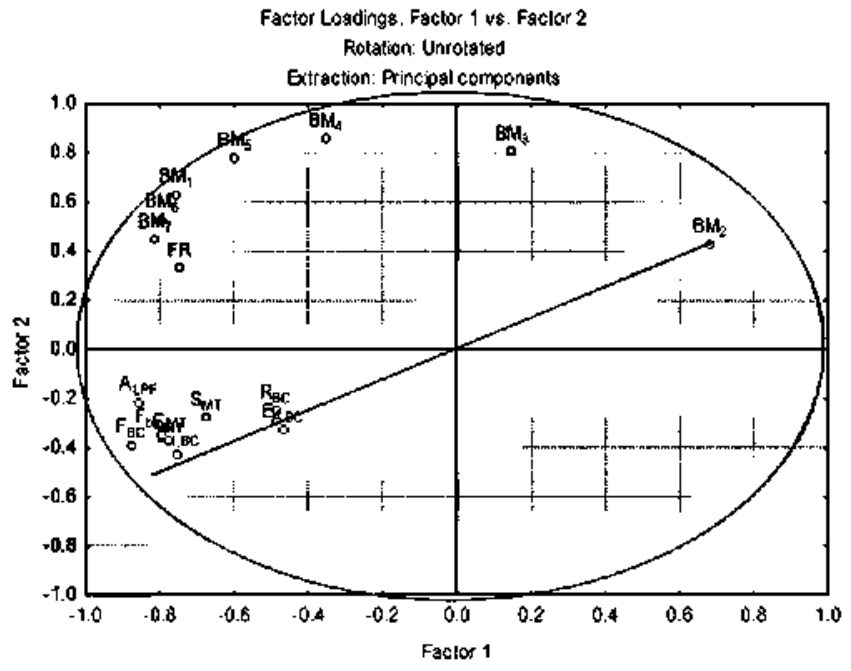

Fig. 3. Principal components analysis plot using all the acquired data $(n=480)$. Variables extracted from the reference and non destructive tests are represented in a space formed by Factor 1 and Factor 2 of the PCA results.

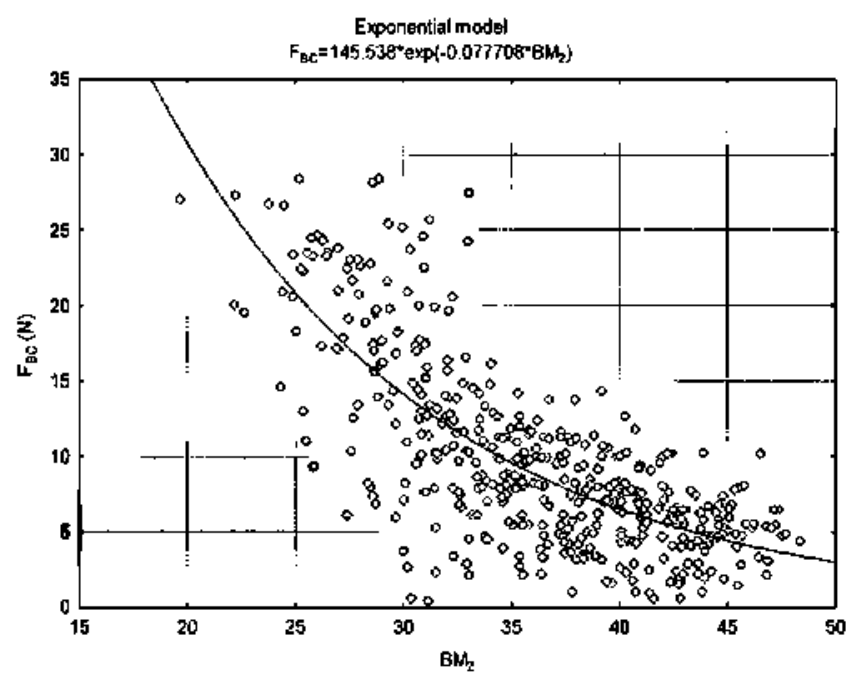

Fig. 5. Exponential model. Dependent variable maximum force in ball compression. $F_{\mathrm{BC}}$; independent variable: band magnitude between 40 and $90 \mathrm{~Hz} . \mathrm{BM}_{2}$.

Table 2

Correlation coefficients between non-destructive and destructive firmness variables

\begin{tabular}{|c|c|c|c|c|c|c|c|c|c|}
\hline & $\mathrm{BM}_{2}$ & $\begin{array}{l}\text { Max acceleration } \\
A_{\text {LPF }}\end{array}$ & $\begin{array}{l}\text { Force } \\
\mathrm{BC} F_{\mathrm{BC}}\end{array}$ & $\begin{array}{l}\text { Elast } \\
\mathrm{BC} R_{\mathrm{BC}}\end{array}$ & $\begin{array}{l}\text { Area abs. } \\
\text { BC } E_{A . \mathrm{BC}}\end{array}$ & $\begin{array}{l}\text { Area ret. } \\
\mathrm{BC} E_{R, \mathrm{BC}}\end{array}$ & $\begin{array}{l}\text { Slope } \\
\text { M-T } S_{M T}\end{array}$ & $\begin{array}{l}\text { Force } \\
\text { M-T } F_{M T}\end{array}$ & $\begin{array}{l}\text { Force bioy. } \\
\text { M-T } F_{\text {bio.MT }}\end{array}$ \\
\hline $\mathrm{BM}_{2}$ & 1.00 & -0.76 & -0.71 & -0.17 & -0.32 & -0.56 & -0.44 & -0.60 & -0.53 \\
\hline$A_{\mathrm{LPF}}$ & & 1.00 & 0.87 & 0.40 & 0.38 & 0.68 & 0.58 & 0.70 & 0.67 \\
\hline$F_{\mathrm{BC}}$ & & & 1.00 & 0.58 & 0.57 & 0.88 & 0.69 & 0.82 & 0.81 \\
\hline$R_{\mathrm{BC}}$ & & & & 1.00 & 0.18 & 0.47 & 0.51 & 0.56 & 0.60 \\
\hline$E_{A, \mathrm{BC}}$ & & & & & 1.00 & 0.87 & 0.29 & 0.35 & 0.34 \\
\hline$E_{R . \mathrm{BC}}$ & & & & & & 1.00 & 0.58 & 0.67 & 0.67 \\
\hline$S_{\mathrm{MT}}$ & & & & & & & 1.00 & 0.60 & 0.75 \\
\hline$F_{\mathrm{MT}}$ & & & & & & & & 1.00 & 0.95 \\
\hline$F_{\text {bio.MT }}$ & & & & & & & & & 1.00 \\
\hline
\end{tabular}


non-destructive variables to estimate the firmness state of the samples are impact acceleration, $A_{\mathrm{LPF}}$, and $\mathrm{BM}_{2}$.

The correlation matrix of firmness variables was performed using pooled data from experiment $A$ and experiment $B$, and including as non-destructive variables impact acceleration, $A_{\mathrm{LPF}}$, and $\mathrm{BM}_{2}$ (Table 2). These non-destructive variables showed high correlations with the maximum force in ball compression $\left(F_{\mathrm{BC}}\right)$. Regarding their relationship with the reference Magness-Taylor firmness test, correlations of $F_{\mathrm{MT}}$ with both nondestructive parameters are lower, but also highly significant. In all cases, maximum acceleration $\left(A_{\mathrm{LPF}}\right)$ showed the best correlations with reference firmness measurements. Exponential models were fitted to estimate $F_{\mathrm{BC}}$ using $A_{\mathrm{LPF}}$ or $\mathrm{BM}_{2}$ (Figs. 4 and 5). Correlation coefficients $R$ of the models were 0.89 with $A_{\mathrm{LPF}}$, and 0.75 with $\mathrm{BM}_{2}$. In both cases better estimates of $F_{\mathrm{BC}}$ were obtained in exponential models than in linear models.

\subsection{Influence of storage time and impact position on impact and acoustic parameters: variance analysis}

The aim of this analysis was to determine the effect of storage time and of impact position on firmness of stored peaches, in order to verify the sensitivity of impact and acoustic devices to fruit ripeness evolution. Therefore an analysis of variance (ANOVA) was carried out to determine whether the independent variables "day" and "cheek" had a significant influence on acoustic and impact response values. For this analysis, the means of the three measurements per cheek were used.

Not significant differences by cheek were found in all but one cases (Fig. 6). Parameters of Magness-Taylor penetration and ball compression do not show significant differences between the two cheeks. Thus, it can be stated that factor cheek did not seem to have an important influence over firmness values.
Regarding storage day, significant differences can be observed in all cases. Among the non-destructive test, the ANOVA analysis showed that the impact parameter was the best predictor for the storage evolution, according to its highest $F$-value. The values for maximum acceleration decreased when storage days increased. In the acoustic test, $\mathrm{BM}_{2}$ in the frequency ranges 40 $90 \mathrm{~Hz}$, was the parameter with greater differences throughout the period of storage (Fig. 7), consistently for all varieties and storage temperatures.

\subsection{Continuous models for firmness estimation}

\subsubsection{Models using the complete range}

In an attempt of improving the non-destructive estimation of firmness in peaches, models combining impact

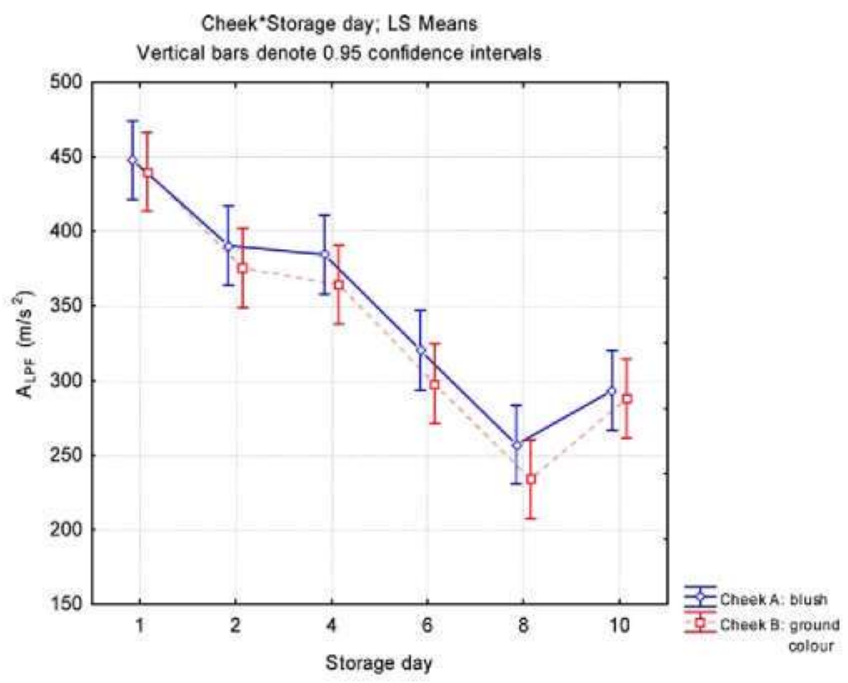

Fig. 6. Mean values of $A_{\mathrm{LPF}}$ for cheek and storage day in 'Rich Lady' peaches stored at $10^{\circ} \mathrm{C}$.
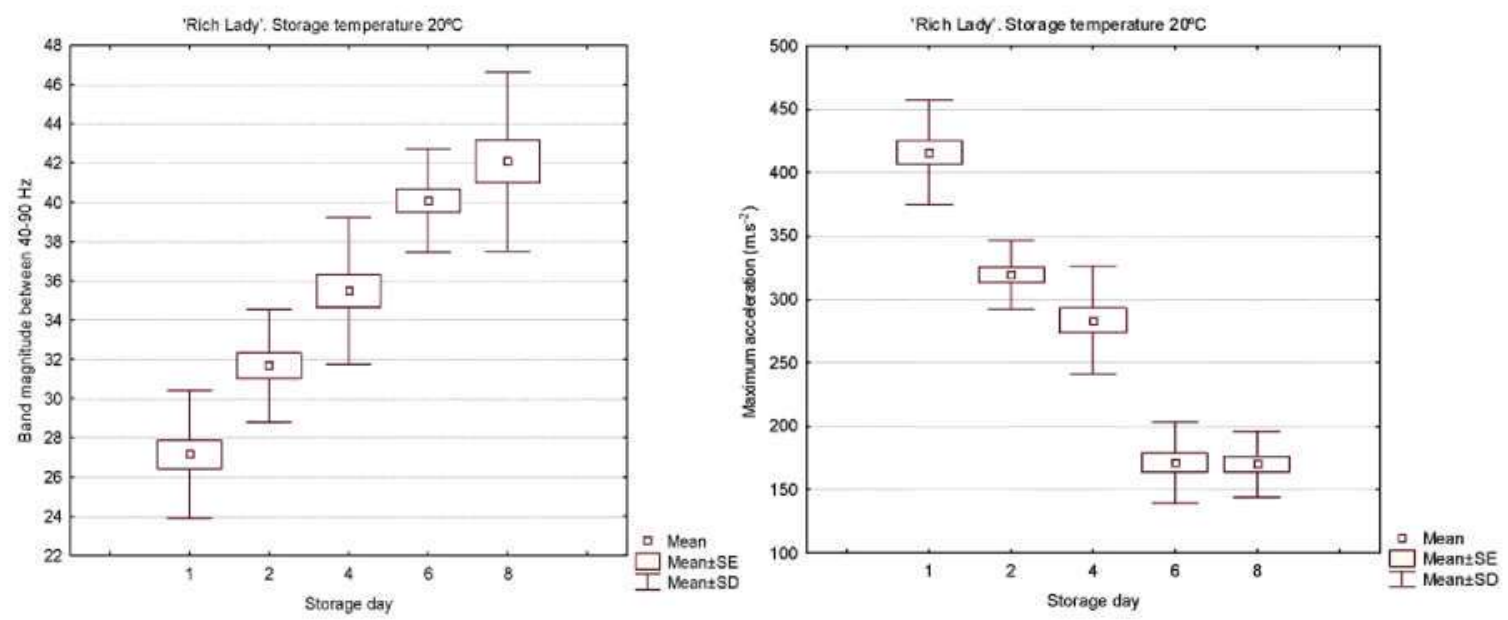

Fig. 7. Mean and standard deviation of the $\mathrm{BM}$ in the frequency ranges $40-90 \mathrm{~Hz}\left(\mathrm{BM}_{2}\right)$ and maximum acceleration for 'Rich Lady' peaches stored at $20^{\circ} \mathrm{C}$. 
Table 3

Polynomial regression model coefficients to estimate maximum force in ball compression, $F_{\mathrm{BC}}$

\begin{tabular}{lc}
\hline$F_{\mathrm{BC}}$ & \\
\hline Intercept & 22.20 \\
$\mathrm{BM}_{2}$ & -1.06 \\
$\mathrm{BM}_{2}^{2}$ & 0.014 \\
$A_{\mathrm{LPF}}$ & -0.018 \\
$A_{\mathrm{LPF}}{ }^{2}$ & 0.00014 \\
\hline
\end{tabular}
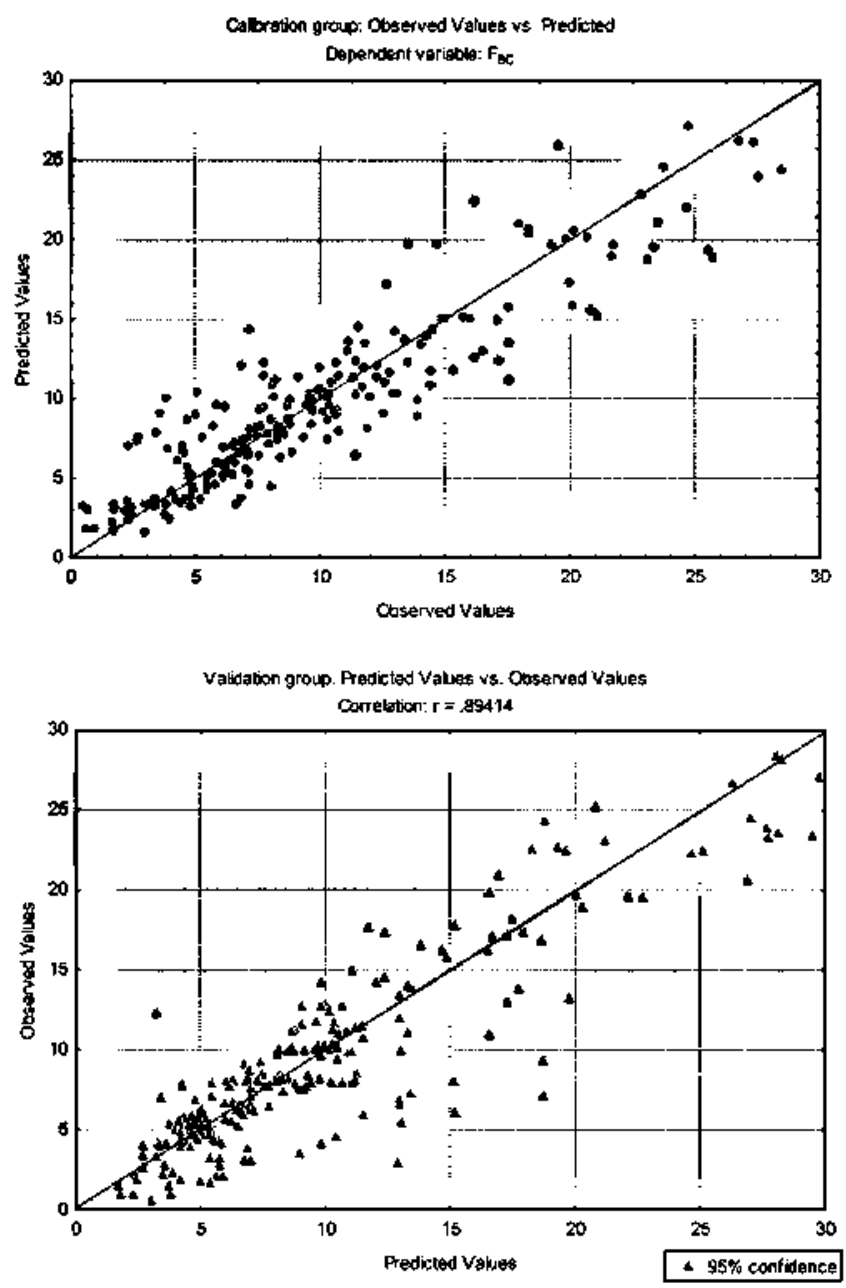

Fig. 8. Scatterplot: predicted values vs. observed values of maximum force in ball compression. Predicted values estimated using polynomial regression model. Calibration and validation groups.

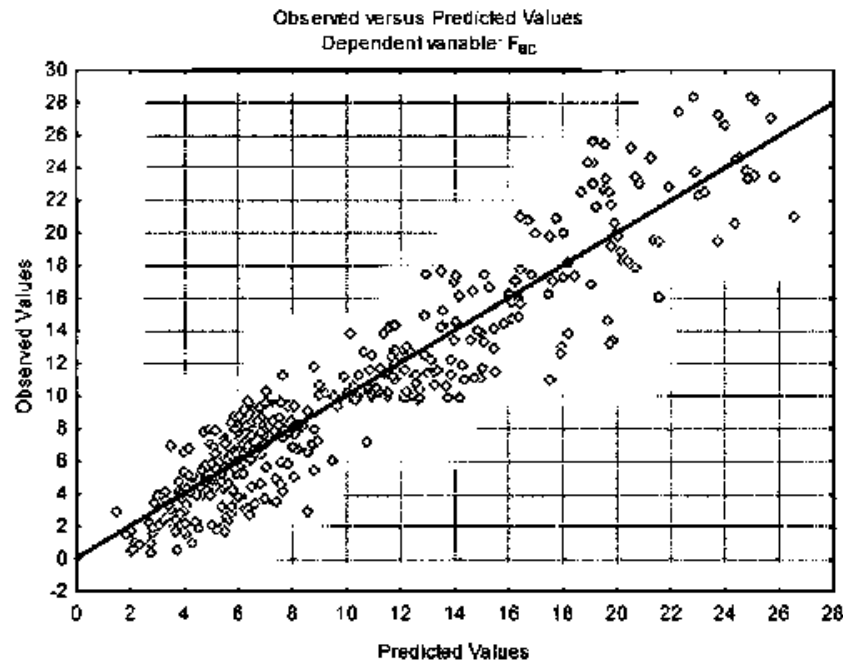

Fig. 9. Observed vs. predicted $F_{\mathrm{BC}}$ value. Piecewise linear regression with breakpoint: $A_{\mathrm{LPF}}$ and $\mathrm{BM}_{2}$. as independent variables.

and acoustic parameters were tested. The population was randomly divided in two groups: calibration and validation groups. The first one was used to generate models, which were applied to the validation group. The best results were obtained with a polynomial regression model, where the maximum force in compression was predicted by means of a regression design which contains main effect (first-order effect) of $A_{\mathrm{LPF}}$ and $\mathrm{BM}_{2}$, and their quadratic effects. The multiple correlation coefficient $R$ of the model was 0.92 , and its adjusted coefficient of determination $R^{2} 0.83$ (Table 3). Fig. 8 (top) shows the scatter plot of observed values versus predicted values of the calibration group. Observed values were achieved applying the estimation model obtained with the calibration group to the validation group (Fig. 8, bottom). With the same predictors, the estimation of $F_{\mathrm{MT}}$ showed a multiple correlation coefficient of 0.67 .

\subsubsection{Segmented estimation models: piecewise linear regression with breakpoint}

When the $F_{\mathrm{MT}}$ was selected as reference variable, and $\mathrm{BM}_{2}$ and $A_{\mathrm{LPF}}$ were used as explaining variables, a model resulting in $R=0.89$ and an explained variance of $79.9 \%$ was achieved (Table 4 ). Changes in the breakpoint values decreased the $R$ and the explained variance.

Table 4

Multiple linear regression models with breakpoint using $\mathrm{BM}_{2}$ and $A_{\mathrm{LPF}}$ to estimate $F_{\mathrm{MT}}$ (first rows) and $F_{\mathrm{BC}}$

$\begin{array}{lllllll}\text { Const. B0 } & \mathrm{BM}_{2} & A_{\mathrm{LPF}} & \text { Const. B0 } & \mathrm{BM}_{2} & A_{\mathrm{LPF}} & \text { Breakpt. }\end{array}$

Model is: Piecewise linear regression with breakpoint; Dependent variable: $F_{\mathrm{MT}}$; Loss: Least squares; Final loss: $10324.72 ; R=0.89$;

Variance explained: $79.9 \%$
Estimate
$-11.21$
0.234
0.0321
22.331
$-0.301$
0.036
13.898

Model is: Piecewise linear regression with breakpoint; Dependent variable: $F_{B C}$ : Loss: Least squares; Final loss: $1885.69: R=0.94:$

Variance explained: $88.7 \%$

Estimate $\quad-4.099$

0.053

0.032

$-2.433$

$-0.201$

0.068 


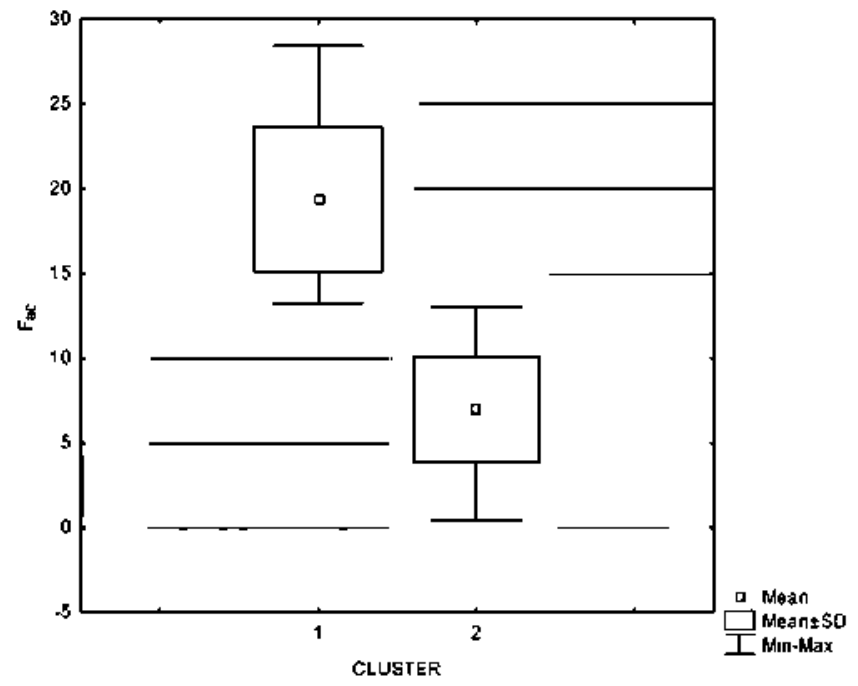

Fig. 10. Mean values and range of clusters according to maximum force in compression with ball test (observed categories) used to build the classification model into two firmness level.

Table 5

Classification matrix for firmness estimation using $A_{\mathrm{LPF}}$ and $\mathrm{BM}_{2}$

\begin{tabular}{llccl}
\hline & $\begin{array}{l}\text { Well } \\
\text { classified (\%) }\end{array}$ & Cluster l & Cluster 2 & $\begin{array}{l}\text { Mean } F_{\text {BC }} \text { for } \\
\text { each cluster }(\mathrm{N})\end{array}$ \\
\hline Cluster 1 & 76.7 & 76 & 23 & 19 \\
Cluster 2 & 97.3 & 9 & 330 & 6.5 \\
Total & 92.7 & 85 & 353 & \\
\hline
\end{tabular}

Clusters from the non-supervised division in two groups of the database according to the maxinum force in compression with ball. Rows: observed clusters. columns: estimated group ascription.

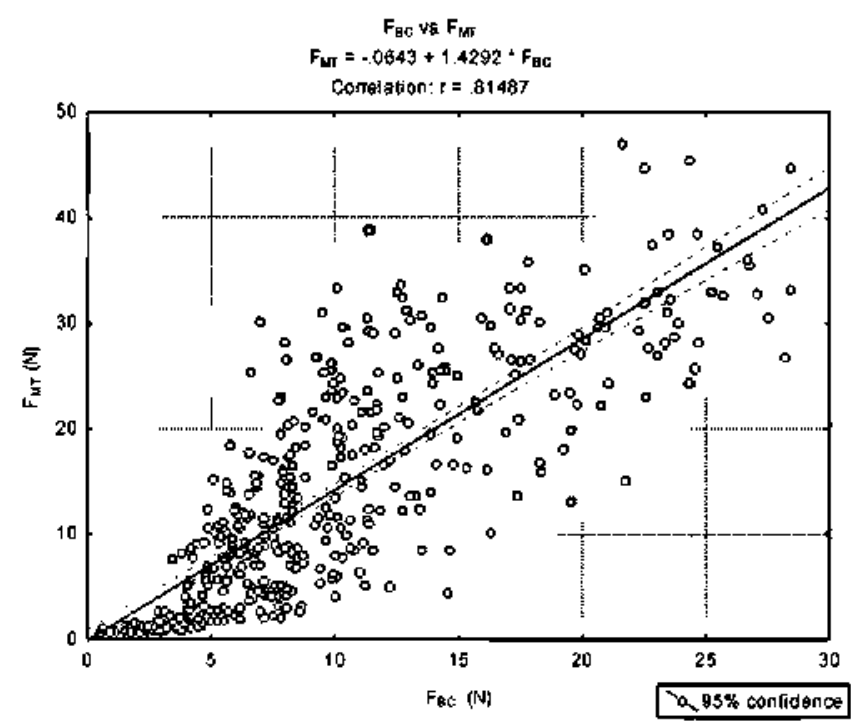

Fig. 11. Maximum force in the Magness-Taylor test compared to maximum force in the compression with ball test.
Table 6

Classification matrices for firmness estimation using $A_{\mathrm{LPF}}$ and $\mathrm{BM}_{2}$

\begin{tabular}{llrcl}
\hline & $\begin{array}{l}\text { Well } \\
\text { classified (\%) }\end{array}$ & Cluster 1 & Cluster 2 & $\begin{array}{l}F_{\mathrm{BC}} \text { values for } \\
\text { each cluster (N) }\end{array}$ \\
\hline Cluster 1 & 86.5 & 32 & 5 & $>16 \mathrm{~N}$ \\
Cluster 2 & 96.7 & 6 & 176 & $<16 \mathrm{~N}$ \\
Total & 95 & 38 & 181 & \\
Cluster 1 & 69.4 & 25 & 11 & $>16 \mathrm{~N}$ \\
Cluster 2 & 98.4 & 3 & 180 & $<16 \mathrm{~N}$ \\
Total & 93.6 & 28 & 191 & \\
\hline
\end{tabular}

Clusters from the division in two groups of the database according to the maximum force in compression with ball. Threshold according to literature. Rows: observed clusters, columns: estimated group ascription. Calibration group (top): validation group (bottom).

Also in this case, when the maximum force in the compression with ball test was explained using $\mathbf{B M}_{2}$ and $A_{\text {LPF, }}$, the model showed much better fit $(R=0.94)$ and an explained variance of $88.7 \%$, for a breakpoint of $9.76 \mathrm{~N}$ (Fig. 9 and Table 4).

\subsection{Classification models for firmness estimation}

In a first approach, the database was divided in two groups according to their firmness, using non-supervised clustering techniques and the maximum force in compression with ball as independent variable. The two resulting clusters were not overlapped, and had an average value of 6.9 and $19.4 \mathrm{~N}$, respectively (Fig. 10), with a threshold of $12 \mathrm{~N}$ between the clusters.

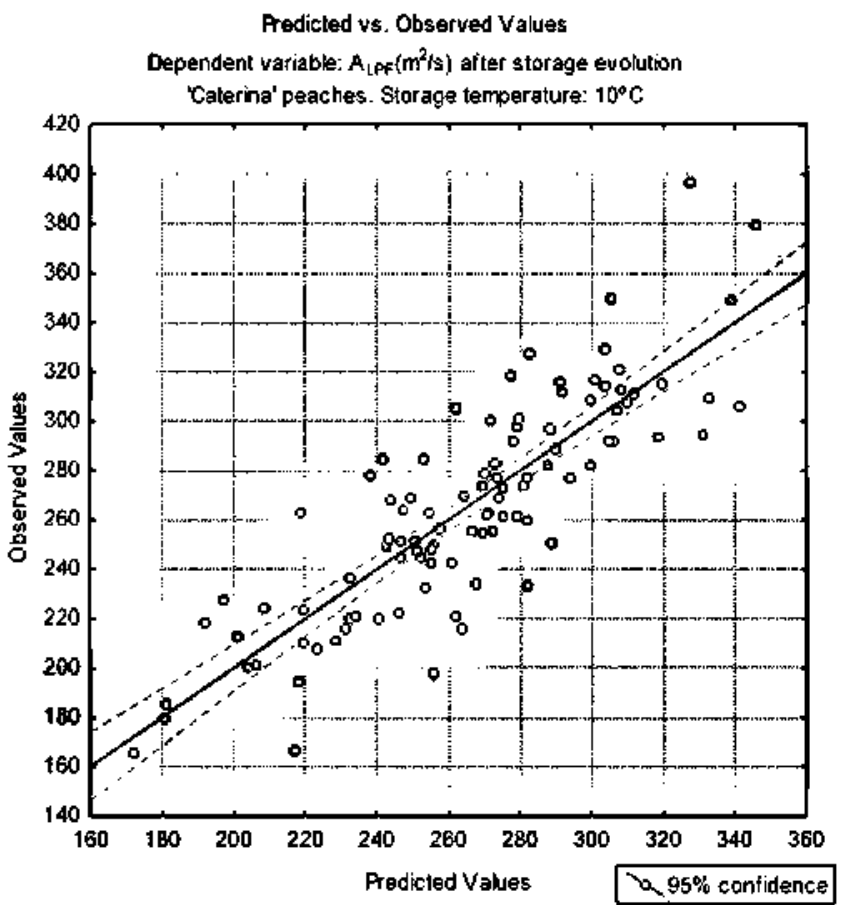

Fig. 12. Observed vs, predicted $A_{\mathrm{LPF}}$ value after storage period. Multiple linear regression model with $A_{\mathrm{LPF}}$ at the first day and the storage day when each fruit was destructed. as independent variables. 
Table 7

Multiple linear regression model using $A_{\text {LPF }}$ registered during the first day of measurements and the storage day when each fruit was destructed to estimate $A_{\mathrm{LPF}}$ measured in the last day of storage for each peach

\begin{tabular}{|c|c|c|c|c|c|c|}
\hline & Beta & Std. Err. & B & Std. Err. & $\mathbf{t}(97)$ & $p$-Level \\
\hline \multicolumn{7}{|c|}{ Regression summary for dependent variable: $A_{\mathrm{LPF}}: R=0.84897375 ; R^{2}=0.72 ;$ Adjusted $R^{2}=0.71 ; F(2.97)=125.18 \mathrm{p}$} \\
\hline Intercept & & & 107.03 & 19.09 & 5.60 & 0.000000 \\
\hline$A_{\mathrm{LPF}}$ & 0.62 & 0.053 & 0.66 & 0.057 & 11.58 & 0,000000 \\
\hline Storage day & -0.57 & 0.053 & -8.79 & 0.82 & -10.63 & 0,000000 \\
\hline
\end{tabular}

Discriminant functions were created to sort peaches matching the clusters, using acoustic and impact variables. Classification results (not shown) when $\mathbf{B M}_{2}$ was used as the only dependent variable were lower ( $87.7 \%$ of correctly classified samples) than when the $A_{\mathrm{LPF}}$ impact variable was used as single predictor $(91.8 \%)$. If both variables were combined in the classification model (Table 5), the result was slightly better and satisfactory $(92.7 \%)$ for an industrial application.

In order to focus the study towards an industrial usage, threshold values for the groups were selected according to literature (Crisosto, Slaughter, Garner, \& Boyd, 2001). For classification into two firmness groups, limits of $22 \mathrm{~N}$ of $F_{\mathrm{MT}}$ has been proposed, which correspond in our case to $16 \mathrm{~N}$ of $F_{\mathrm{BC}}$ (Fig. 11). Using this threshold, new classification models were established, achieving the elimination of soft fruits.

Classification using $\mathrm{BM}_{2}$ and $A_{\mathrm{LPF}}$ as predictor resulted in $95 \%$ of well classified peaches with half of the database (Table 6) (validation of $93.6 \%$ of well classified with the rest of the database).

\subsubsection{Storage and shelf life evohtion models}

For the non-destructive prediction of firmness evolution of stored peaches, multiple linear regression models were performed for each of the four combinations of variety and storage temperature. The independent variables in these models were: impact acceleration, $A_{\mathrm{LPF}}$, registered during the first day; storage day when each fruit was destructed. The predicted variable was the $A_{\mathrm{LPF}}$ value of the fruit on and arbitrary day of storage.

The most accurate model was obtained for 'Caterina' peaches, stored at $10^{\circ} \mathrm{C}$ (Fig. 12), which showed a multiple $R$ of 0.85 and an adjusted $R^{2}$ of 0.71 (Table 7 ). Similar results were obtained in the other cases, except for 'Rich Lady' stored at $10^{\circ} \mathrm{C}$, where the range of variation of firmness was significantly lower. Although modelling the decrease of firmness in time has reported acceptable results in some cases, the model should be adjusted for every batch of fruit and storage conditions.

\section{Conclusions}

Two non-destructive techniques were used for firmness measurement in peaches. Parameters obtained for the output signal of each system were compared to destructive reference tests.

The maximum force in ball compression correlated very well with the maximum acceleration from impact test $\left(r=0.87\right.$ and $\left.r^{2}=0.75\right)$, and showed reasonable correlation with the $\mathrm{BM}_{2}$ from the acoustic test $(r=-0.71)$.

Combining impact and acoustic parameters, the multiple correlation coefficient increases up to 0.91 (adjusted $R^{2}=0.82$ ) in the prediction of the force of the compression with sphere to $2 \mathrm{~mm}$ deformation. These findings indicate that the fusion of impact and acoustic tests shows good possibilities for improving a sorting system for sensing firmness in peaches.

Classification models sorting peaches into two classes of firmness regarding the maximum force of the compression with ball test, showed the best scores of well classified samples if $\mathrm{BM}_{2}$ and $A_{\mathrm{LPF}}$ variables were combined (more than 93\%).

The pattern of the evolution of firmness in storage is very different between varieties. Higher number of measurements is required to perform accurate models. The tracking of changes of individual fruits during storage and shelf-life may improve the models for firmness evolution. In spite of this, acceptable storage evolution models ( $R^{2}$ of 0.71 ) was obtained for one combination of variety and storage temperature. $A_{\mathrm{IPF}}$ values after storage period were estimated as a function of $A_{\mathrm{LPF}}$ at the beginning and number of days of storage.

\section{Acknowledgements}

We thank the Spanish Ministry of Education and Science for funding.

\section{References}

Abbott. J. A., Bachman, G. S., Childers, R. F., \& Fitzgerald, J. V. (1968). Sonic techniques for measuring texture of fruits and vegetables. Food Technology, 22. 635-646.

Armstrong, P. R., Stone, M. L.. \& Brusewitz, G. H. (1997). Peach firmness determination using two different nondestructives vibrational sensing instruments. Transactions of the ASAE, $40(3)$. 699-703. 
Carlomagno. G., Capozzo, L.. Attolico. G.. \& Distante, A. (2005). Non-destructive grading of peaches by near-infrared spectrometry. Infrared Physics and Technology, 46(2004), 23-29.

Cooke, J. R. (1972). An interpretation of the resonant behaviour of intact fruits and vegetables. Transactions of the ASAE, $15(6)$, $1075-1080$.

Chen, P., \& Ruiz-Altisent, M. (1993). Effect of impacting mass on firmness sensing of fruits. ASAE paper no. 93-6542.

Chen. P., \& Ruiz-Altisent. M. (1996). A low-mass impact sensor for high-speed firmness sensing of fruits. Paper presented at AgEng96, Madrid, Spain, Paper no. 96F-603.

Crisosto. C. H.. Slanghter, D.. Garner, D., \& Boyd, J. (2001). Stone fruit critical bruising thresholds. Journal of American Pomology Society, 55, 76-81.

De Baerdemaeker. J., Lemaitre, L., \& Meire. R. (1982). Quality detection by frequency spectrum analysis of the fruit impact force. Transactions of the ASAE, 25(1), 175-178.

De Belie. N., Schotte, S., Coucke, P., \& De Baerdemaeker, J. (2000). Development of an antomated monitoring device to quantify changes of firmness of apples during storage. Postharvest Biology and Techology, 18(1), 1-8.

De Ketelaere, B., Ruiz-Altisent, M.. Correa, E. C... De Baerdemaeker, J., \& Barreiro, P. (2001). Reliability of vibration Measurements and Impact Response Characteristics for the Quality Assessment of Tonatoes. Paper presented at 6th international symposium on fruit. nut and vegetable production engineering, Potsdam. Germany. pp. $487-492$.

Delwiche, M. J., MacDonald, T., \& Bowers. S. V. (1987). Determination of peach firmness by analysis of impact forces. Transactions of the ASAE, 3011). 249-254.

Delwiche, M. J., Arévalo. H., \& Mechlschau. J. (1996). Second generation impact force response fruit firmness sorter. Transactions' of the ASAE, 39(3). 1025-1033.

Diezma, B.. Flores. L.. Diez, J., Ruiz-Altisent. M., Barreiro, P., \& Marańón. A. (2000). New Version of a Laboratory Impact Device for Firmness Sensing of Fruits. Paper presented at AgEngOO, Warwick, UK, Paper no, 00-PH-036.

Diezma. B., Ruiz-Altisent, M., \& Orihuel, B. (2002). Acoustic Inpulse Response for Detecting Hollow Heart in Seedless Watermelon.
Actas Horticulturae 599: Proceedings of the postharest anlimited, Letwen, Belgium (pp. 249-256).

Diezma, B. (2003). Detección no destructiva de problemas de calidad interna en sandias apirenas mediante respuesta acística a impactos de baja intensidad (Non-destructive detection of internal quality problems in seedless watermelons by impact acoustic response). Ph. D. Thesis. Polytechnic Cniversity of Matrid.

Diezma-Iglesias, B.. Ruiz-Altisent, M.. \& Barreiro, P. (2004). Detection of internal quality in seedless watermelon by acoustic impulse response. Biosystem Engineering, 88(2), 221-230.

Farabee, M. L. \& Stone, M. L. (1991). Determination of Watermelon Maturity with Sonic Inpulse Testing. ASAE meeting presentation. Paper no, 91-3013.

García-Ramos. F. J., Ortiz-Caňavate, J., Ruiz-Altisent. M., Díez. J., Flores, L.. Homer, L. \& Chávez, J. M. (2003). Development and implementation of an on-line impact sensor for firmmess sensing of fruits. Jounal of Food Engineering. 58(2003), 53-57.

Homer, I. (2003). Desarrollo y aplicación de un sensor de impacto para la determinación de firmeza en líneas de manipulación de fruta (Development and applicationn of an on-line sensor for firmness sensing of fruits). Ph.D. Thesis. Polytechnic University of Madrid.

Jarén. C.. Ruiz-Altisent. M.. \& Pérez de Rueda. R. (1992). Sensing physical stage of fruits by their response to non-destructive impacts. Paper presented at AgEng92. UPSALA, Paper no, 9211-113.

Ruiz-Altisent. M.. Lleó. L., \& Riquelme. F. (2005). Instrumental quality assessment of peaches: fusion or optical and mechanical parameters. Journal of Food Engineering, (2005). Available online at www.sciencedirect.com.

Shmulevich, I. (1998). A review firmness quality measurements in fruits and vegetables. SENSORAL 98 . Paper presented at international workshop on sensing quality of agrictitural products, Montpellier. France (pp. 291-322).

Valero. C.. García-Ramos. F. J., De Merlo, B., Ruiz-Altisent, M., \& Howarth. S. (2004). Comparison between Sincair IQ firmness tester and standard destructive tests on peaches. Paper presented at AgEng04, Letten, Belgitut, Book of abstract Part 2 (pp. 964-965).

Wang, J.. Teng, B.. \& Yu, Y, (2005). The firmness detection by excitation dynanic characteristics for peach. Food Control. Available online at www.sciencedirect.com. 